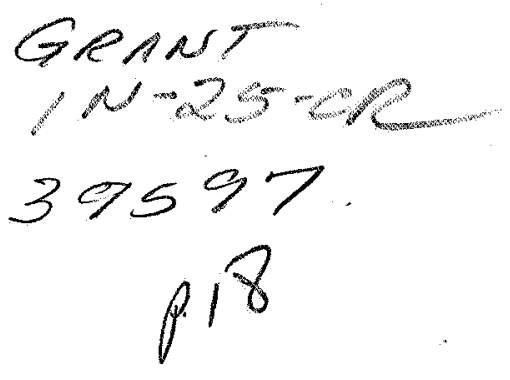

Final Technical Report

for

NASA Grant NAG3-966

\title{
Laser Induced Spark Ignition of Methane-Oxygen Mixtures
}

\author{
Prepared by: D. A. Santavicca \\ C. Ho \\ B. J. Reilly \\ T.-W. Lee \\ Propulsion Engineering Research Center \\ Penn State University
}

Technical Monitor: Elizabeth Armstrong-Roncace

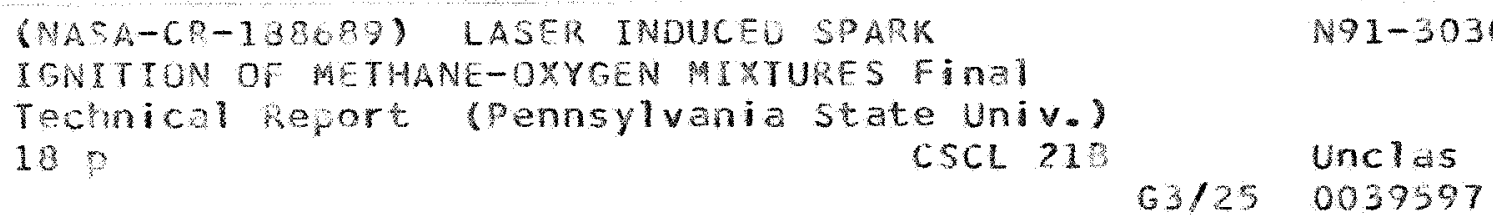




\title{
LASER INDUCED SPARK IGNITION OF METHANE-OXYGEN MIXTURES
}

\author{
C.M. Ho \\ B.J. Reilly \\ T.-W. Lee \\ D.A. Santavicca \\ Turbulent Combustion Laboratory \\ Department of Mechanical Engineering \\ Propulsion Engineering Research Center \\ Penn State University
}

\begin{abstract}
The results from an experimental study of laser induced spark ignition of methane-oxygen mixtures are presented. The experiments were conducted at atmospheric pressure and 296K under laminar-premixed and turbulent-incompletely mixed conditions. A pulsed, frequency doubled Nd:YAG laser was used as the ignition source. Laser sparks with energies of $10 \mathrm{~mJ}$ and $40 \mathrm{~mJ}$ were used, as well as a conventional electrode spark with an effective energy of $6 \mathrm{~mJ}$. Measurements were made of the flame kernel radius as a function of time using pulsed laser shadowgraphy.

The initial size of the spark ignited flame kernel was found to correlate reasonably well with breakdown energy as predicted by the Taylor spherical blast wave model. The subsequent growth rate of the flame kernel was found to increase with time from a value less than to a value greater than the adiabatic, unstretched laminar growth rate. This behavior was attributed to the combined effects of geometric flame stretch and an apparent wrinkling of the flame surface due to the extremely rapid acceleration of the flame. The very large laminar flame speed of methane-oxygen mixtures appears to be the dominant factor affecting the growth rate of spark ignited flame kernels, with the mode of ignition having a small effect. The effect of incomplete fuel-oxidizer mixing was found to have a significant effect on the growth rate, one which was greater than could simply be accounted for by the effect of local variations in the equivalence ratio on the local flame speed.
\end{abstract}




\section{Introduction}

Successful ignition of most combustion systems, including liquid fueled rocket engines, depends not only on the ignition of the local fuel-oxidizer mixture, but also on the ability of the spark ignited flame kernel to propagate from the point of ignition to the flame stabilization region. In many combustion systems it is in fact flame propagation rather than ignitability which determines the ignition limits.

Two obvious methods for extending the ignition limits under such conditions are to increase the flame kernel growth rate and/or to simply ignite closer to the recirculation zone where the flame is stabilized. A number of advanced ignition concepts have been proposed for application to liquid fueled rocket engines including catalytic ignition, hypergolic ignition, plasma jet ignition and laser ignition'. Among these, laser ignition is of particular interest because of the ability to direct the laser beam and thereby ignite at any location within the combustion chamber. Laser ignition also has the potential advantage of use with multicompartment or baffled combustion chambers where simultaneous ignition at a large number of separate locations is required. For example, the output from a single laser could be split and sent through optical fibers to simultaneously ignite each engine compartment.

There are three different mechanisms by which laser induced ignition is possible: laser induced photochemical ignition $^{2-4}$, laser induced thermal ignition ${ }^{5-8}$ and laser induced spark ignition ${ }^{9-17}$. Laser induced photochemical ignition refers to the use of either infrared or ultraviolet multiphoton absorption to photodissociate specific molecular species and thereby create a highly reactive gas mixture which is capable of ignition and sustained combustion. Laser induced thermal ignition refers to the use of infrared absorption, typically of the 10.6 micron output of $\mathrm{C} \mathrm{CO}_{2}$ laser, to vibrationally excite specific molecular species. The vibrationally excited molecules then rapidly dissipate their vibrational energy and thermally heat the gas to the point of thermal ignition. Laser induced spark ignition refers to the use of a high power, pulsed laser to produce large electric field strengths which cause local gas breakdown. The resultant spark discharge generates a high temperature plasma which then ignites the gas mixture. Laser induced spark 
ignition, unlike laser induced photochemical and thermal ignition, can be achieved with infrared, visible or ultraviolet radiation.

In the experimental study which is presented in this paper, the use of laser induced sparks to ignite methane-oxygen mixtures was investigated. The decision to use laser induced spark ignition was based on the practical advantages of using visible rather than ultraviolet or infrared radiation. The possible use of laser induced spark ignition in liquid propellant rocket engines raises a number of fundamental and practical questions. These include:

i. What is the minimum ignition energy?

ii. What is the spark efficiency, i.e., the ratio of the energy deposited to the incident energy?

iii. What is the effect of ignition energy on the initial size and growth rate of laser induced spark ignited flame kernels?

iv. What are the effects of the focusing lens focal length and the laser wavelength?

v. What are the effects of turbulence and incomplete fuel-oxidizer mixing?

vi. How does laser induced spark ignition compare to conventional electrode spark ignition? The objective of this study was to address these questions.

\section{Description of Experiment}

Experiments were conducted at 1 atmosphere and 296K under both laminar and turbulent flow conditions in the experimental apparatus illustrated schematically in Figures 1 and 2, respectively. The laminar test section was $12 \mathrm{~cm}$ by $1.3 \mathrm{~cm}$ in cross-section and $15 \mathrm{~cm}$ high. Methane and oxygen were individually metered and then mixed in a $4 \mathrm{~mm}$ diameter by $2 \mathrm{~m}$ long tube. The premixed methane and oxygen entered a reservoir and then flowed through a sintered bronze plate into the test section where the gas velocity was $4 \mathrm{~cm} / \mathrm{sec}$. The sintered bronze plate served both to laminarize the flow and as a flashback arrester. Optical access for the shadowgraph measurements was provided by two $12 \mathrm{~cm}$ square by $0.6 \mathrm{~cm}$ thick plexiglass windows, while access was available in the test section side walls for the spark electrodes or 
the ignition laser beam. Note that plexiglass windows were used rather than glass windows because they were found to be more resistant to the mechanical shock following the ignition of methane-oxygen mixtures. In addition, and contrary to initial expectations, the plexiglass windows showed little effect from the high burned gas temperatures. In fact, they could be used for as many as 50 ignition events before showing any evidence of distortion or surface degradation in the shadowgraph images. This is apparently due to the fact that the plexiglass was only exposed to the high temperature gas for a few milliseconds.

The turbulent test section was $12 \mathrm{~cm}$ by $1.6 \mathrm{~cm}$ in cross-section and $12 \mathrm{~cm}$ high. Turbulence was generated using a recently developed turbulence generator ${ }^{18}$ which is capable of producing turbulent flows with relative turbulence intensities up to $50 \%$ which are uniform to within \pm 10 percent over the test section cross section. Oxygen was admitted upstream of the turbulence generator, and methane was introduced immediately downstream of the vortex generating slot plate as shown in Figure 2. The reason for introducing methane at this location was to achieve some degree of incomplete fuel-oxidizer mixing so its effect on ignition could be investigated. Attempts were also made to run with premixed methane and oxygen; however, due to flashback through the turbulence generator, this was not possible. The turbulence properties in the test section were measured with laser Doppler velocimetry. The turbulence condition used in this study had a mean velocity of $1 \mathrm{~m} / \mathrm{sec}$, a relative turbulence intensity of $50 \%$ and an integral length scale of $5 \mathrm{~mm}$. The degree of methane-oxygen mixing in the turbulent test section was measured by substituting a $1000 \mathrm{PPM} \mathrm{NO}$ in nitrogen mixture for the methane flow and detecting the $\mathrm{NO}_{2}$ fluorescence induced by the $488 \mathrm{~nm}$ output of an argon ion laser. Using this technique, it was determined for the conditions of the turbulent tests that the rms fluctuation in the equivalence ratio was approximately 5 percent.

The test procedure was the same for the laminar and turbulent tests. The oxygen and methane metering valves were preset to the desired flow rates. With the oxygen flow on and the methane flow off, the methane solenoid valve was opened and the methane flow initiated. After purging the system for at least 15 seconds, the ignition system was fired and then the methane solenoid valve was immediately closed. The 
test section was allowed to cool down for several minutes between firings. Tests were run with methaneoxygen equivalence ratios of $0.6,1.0$ and 1.4. The test conditions are summarized in Table 1 where the adiabatic flame temperature $\left(T_{b}\right)$; the ratio of the unburned to burned gas density $\left(\rho_{w} \rho_{b}\right)$; the unstretched adiabatic laminar flame speed $\left(\mathrm{S}_{\mathrm{L}}\right)$; and the unstretched, adiabatic, laminar, spherical flame kernel growth rate $\left(\dot{\mathrm{R}}_{\mathrm{Lam}}\right)$.

Both laser induced and electrode sparks were used in this study. In both cases, the spark was positioned in the center of the test section. The output of a pulsed (10 nsec), frequency doubled (532nm) Nd:YAG laser was used to produce the laser induced spark. The laser beam was brought to a focus with a $75 \mathrm{~mm}$ focal length plano-convex lens which produced a theoretical divergence limited beam waist of 75 microns. The energy deposited by the laser spark was determined by measuring the laser pulse energy before and after the laser spark using a calorimetric power meter. This technique provided a measure of the average energy per pulse, however, previous single pulse measurements made using calibrated photo-diode detectors indicated that the shot-to-shot variations in the energy deposited by the laser spark were less than \pm 10 percent. The spark efficiency can be defined as the difference between the laser pulse energy before and after the spark divided by the laser pulse energy before the spark. Laser-induced spark energies, i.e. the energy deposited, of $10 \mathrm{~mJ}$ and $40 \mathrm{~mJ}$ were used in this study where the spark efficiencies were approximately $50 \%$ and $70 \%$, respectively. Note that the spark efficiency was found to increase with laser pulse energy until reaching a constant value of around 70 to 80 percent as shown in Figure 3 . It was also found that the effective minimum ignition energy was approximately $1.5 \mathrm{~mJ}$, where this limit was not determined by the ignitability of the gas mixture but by the ability to achieve gas breakdown and actually produce a spark. It is reasonable to expect that this result would depend somewhat on the laser wavelength and the focal length of the focusing lens, however, this was not investigated in this study.

The electric spark was produced with an inductive-type automotive ignition system, i.e. a General Motors HEI system. The high voltage and ground electrodes were identical $0.4 \mathrm{~mm}$ diameter by $60 \mathrm{~mm}$ long steel wires which were tapered to a point and positioned to give a $1 \mathrm{~mm}$ spark gap. The voltage and current 
of the spark discharge were measured using a high voltage probe and an inductive current probe, respectively. The total energy deposited (averaged over ten ignition events), including both the breakdown $(0.8 \mathrm{~mJ})$ and glow discharge $(58.2 \mathrm{~mJ})$ phases, was $59 \mathrm{~mJ}$. A considerable portion of this energy, however, is lost as heat to the electrodes ${ }^{20}$. Again one can define a spark efficiency, which in this case is the energy which actually goes into the gas divided by the total energy supplied to the spark. Based on spark efficiency measurements of other researchers ${ }^{20}$, the actual amount of spark energy deposited in the gas was $6 \mathrm{~mJ}$. Note that the duration of the electrode spark was approximately 7 milliseconds as compared to the 10 nanosecond duration of the laser induced spark.

The growth of the spark ignited flame kernel was characterized using pulsed laser shadowgraphy. A second frequency doubled, pulsed Nd:YAG laser was used for the shadowgraph light source and the shadowgraph image was directly recorded with a CCD camera-frame grabber system. The laser and camera were synchronized with the firing of the ignition system, but were delayed in time to obtain shadowgraph images of the flame kernel at specific times following the start of ignition. Only one image was recorded from each ignition event, therefore the flame kernel radius versus time results were reconstructed from measurements from different ignition events. Typically five measurements were made at each time delay which gave an indication of the repeatability of the ignition process. In order to quantify the size of the flame kernel, enlarged hardcopies of the individual digital images were obtained and the boundaries of the flame kernels were manually digitized with a digitizing tablet. The projected area of the flame kernel shadowgraph image was calculated and then equated to the area of a circle from which an equivalent flame kernel radius was calculated.

\section{Results and Discussion}

The laser spark and electrode spark ignition results are plotted in terms of the equivalent flame kernel radius versus time following the start of ignition for the laminar case in Figures 4-6 and for the turbulent case in Figure 7. Also shown for comparison in the laser spark cases are the results with 100 percent oxygen, i.e., no methane. 
A common characteristic of all the results is that at the start of ignition there is a nearly instantaneous growth of the plasma kernel to an initial finite size. This growth can be attributed to the sudden deposition of energy during the breakdown process which generates a high pressure in the plasma kernel which drives a rapidly expanding blast wave. The initial growth of the plasma kernel can therefore be predicted by blast wave theory, ${ }^{21}$ assuming that the heat release due to chemical reactions is negligible up to this time. Shadowgraph images of the laser induced spark kernel at 50 nanoseconds and at 1,5 and 10 microseconds are shown in Figure 8. These images show for the case of laser induced spark ignition that the ignition kernel is somewhat cylindrical at 50 nanoseconds, but by 1 microsecond it appears to be relatively spherical. (Note that the direction of propagation of the laser ignition beam was from left to right in these figures.) It is reasonable therefore to compare the measured "initial" (e.g., at 1 microsecond) flame kernel radius to that predicted by the Taylor spherical blast wave model,,$^{21}$ i.e.,

$$
R=\left(\frac{E}{\rho_{0}}\right)^{0.2} t^{0.4}
$$

where $\mathrm{E}$ is the breakdown energy, $\rho_{\mathrm{o}}$ is the gas density before ignition and $\mathrm{t}$ is the time following the initiation of gas breakdown. A comparison between the measured plasma kernel radius at 1 microsecond for the three ignition conditions (at $\phi=1.0$ ) and the predictions of the Taylor spherical blast wave model is given in Table 2. Both the measured and predicted plasma kernel radii increase with increasing breakdown energy; however, the measured radius is approximately 30 percent greater than the predicted radius in all three cases. This is perhaps due to the fact that the blast wave is actually somewhat cylindrical in shape before becoming spherical; therefore, the assumption of a point energy source is not entirely valid at these early times. Note, however, that when comparing the ratios of the plasma kernel radius for the different breakdown energies one finds very good agreement with the $E^{0.2}$ dependence predicted by the spherical blast wave model. It is also interesting to note that for the laser induced sparks the plasma kernel radius measured at 1 microsecond is the same for equivalence ratios of $0.6,1.0$ and 1.4 ; whereas at 5 microseconds and later the kernel radius is different for the different equivalence ratios. This indicates that 
the effect of chemical heat release on the initial (i.e., at 1 microsecond) kernel size is negligible, and therefore, the blast wave theory can be used to obtain a reasonable estimate of the initial laser induced spark kernel. On the other hand, in the case of the electrode spark where the breakdown energy was only $0.8 \mathrm{~mJ}$, changes in the equivalence ratio are found to have an appreciable effect on the initial size of the spark ignited flame kernel.

Another common characteristic evidenced in all the cases studied is that following the initial blast wave dominated phase, the flame kernel growth rate increases with time. This is more easily seen in Figures 912 where the flame kernel growth rate normalized by the adiabatic, unstretched laminar flame kernel growth rate is plotted against time. Note that the flame kernel growth rate was obtained by taking the time derivative of the curve fitted through the radius versus time data shown in Figures 4-7. Also note that the adiabatic, unstretched laminar flame kernel growth rate, $\dot{\mathrm{R}}_{\mathrm{Lam}}$ (see Table 1), is given by:

$$
\dot{\mathrm{R}}_{\mathrm{Lam}}=\frac{\rho_{\mathrm{u}}}{\rho_{\mathrm{b}}} \mathrm{S}_{\mathbf{L}}
$$

where $\rho_{\mathrm{u}}$ and $\rho_{\mathrm{b}}$ are the densities of the unburned and burned gas, respectively, and $\mathrm{S}_{\mathrm{L}}$ is the adiabatic, unstretched laminar flame speed. As noted previously, for all conditions tested, i.e., laser spark, electrode spark, laminar, turbulent, lean, rich and stoichiometric, the flame kernel growth rate is observed to increase with time. It is also important to note, however, that the growth rate actually starts out less than, and then after approximately 100 microseconds increases to a value greater than the adiabatic, unstretched, laminar growth rate.

Several factors may contribute to this behavior. One which should not be overlooked is simply the possibility that the methane-oxygen flame speed ${ }^{22}$ reported in Table 1 is incorrect. There are only limited amounts of data on methane-oxygen flame speed, and among them large discrepancies exist. The numbers reported in Table 1 represent an arbitrary choice among the available data. 
A second factor is geometric flame stretch, commonly defined as

$$
\mathrm{K}=\frac{2}{\mathrm{R}} \dot{\mathrm{R}}
$$

for an outwardly propagating spherical flame. For the case with unity Lewis number, we can derive ${ }^{23}$ the flame front velocity (or growth rate) ratio between the outwardly propagating spherical flame and the adiabatic, unstretched flame, i.e.,

$$
\frac{\dot{\mathrm{R}}}{\dot{\mathrm{R}}_{\mathrm{Lam}}}=1-\alpha \mathrm{K}=1-\alpha\left(\frac{2}{\mathrm{R}} \dot{\mathrm{R}}\right)
$$

where $\alpha$ is a positive constant depending on the mixture properties and laminar flame speed. This ratio is less than unity when $\mathrm{R}$ is small. Note, however, that as the flame kernel grows, the geometric stretch decreases. Therefore, the flame kernel growth rate should steadily increase and asymptotically approach the adiabatic, unstretched growth rate, $\dot{\mathrm{R}}_{\mathrm{Lam}}$. However, as noted previously, the measurements show that the growth rate continues to increase beyond that of the adiabatic, unstretched case. Two factors can explain this behavior. First, the laminar flame speed of the unburnt mixture ahead of the flame may have changed due to compression of the gas within the semi-enclosed test section by the rapidly moving flame front. Second, there may be an increase in the surface area of the flame kernel due to flame front instabilities generated by the large acceleration of the flame front. ${ }^{24}$ Evidence of wrinkling is seen in the shadowgraph images, where the degree of wrinkling is also observed to increase with time. This observation may explain the continued increase in the flame kernel growth rate to values greater than $\dot{R}_{\text {Lam }}$.

When the fuel lean cases $(\phi=0.6)$ are compared to the fuel rich cases $(\phi=1.4)$, all the lean cases are found to grow more slowly than the corresponding rich cases. This is unexpected because the value of $\dot{\mathrm{R}}_{\mathrm{Lam}}$ for the lean case is slightly higher than that for the rich case (see Table 1). It is possible that preferential diffusion may have different effects under lean and rich conditions if the Lewis numbers for these mixtures are different from unity. However, the Lewis number calculated for the two-component mixture (methane and oxygen) at $\phi=0.6$ and 1.4 are very similar ( 0.92 and 0.90 , respectively) and are 
very close to unity. Therefore, the Lewis number effect is unlikely to be significant. This again suggests the possibility that the reported laminar flame speeds are not accurate.

An interesting comparison between the growth rate of laser spark ignited flame kernels in methaneoxygen mixtures and methane-air mixtures ${ }^{17}$ is shown in Figures 13 and 14. In the case of methane-oxygen, the growth rate is increasing, whereas in the case of methane-air, it is decreasing and asymptotically approaching the adiabatic, unstretched, laminar growth rate. This markedly different behavior can be attributed to the relative importance of the energy supplied by the laser induced spark as compared to the rate of chemical heat release. In the methane-oxygen case, the effects of the very large flame speed, and in turn, flame kernel growth rate are dominate as described previously. In the methane-air case, the energy supplied by the laser induced spark actually results in a thermally and/or chemically enhanced flame kernel growth rate, ${ }^{17}$ where this effect persists well beyond the 10 nanosecond duration of the laser spark.

A comparison between the $10 \mathrm{~mJ}$ laser spark, $40 \mathrm{~mJ}$ laser spark and the electrode spark for laminar, stoichiometric conditions is shown in Figure 15. The primary difference between these three cases appears to be in the initial size of the flame kernel following the blast wave phase, while the subsequent growth rate is nearly the same. Again this indicates that the very large laminar flame speed of methane-oxygen mixtures is the dominant factor in the growth of spark ignited flame kernels.

The results for the case with turbulence and incomplete mixing were shown in Figure 7. Qualitatively, the behavior is the same as was discussed in the laminar cases. Figure 16 shows a direct comparison between the laminar and turbulent results for the case of a $10 \mathrm{~mJ}$ laser spark and an equivalence ratio of 1.0. As expected, the two cases have the same initial size, however, the turbulent case is observed to grow more slowly than the laminar case. This suggests that for the conditions of this test, the effects of turbulence were negligible, whereas the effect of a 5 percent fluctuation in the equivalence ratio resulted in a pronounced decrease in the growth rate. It is interesting to note that the measured growth rate for a mean equivalence ratio of 1.0 with 5 percent fluctuations due to incomplete mixing is comparable to that for the measured premixed case at an equivalence ratio of 0.6. This indicates that the effect of incomplete fuel- 
oxidizer mixing cannot simply be accounted for by the effect of local variations in the equivalence ratio on the local flame speed.

\section{Acknowledgements}

Support for this research was provided by NASA Lewis Research Center under Grant NAG 3-966 and by the Propulsion Engineering Research Center at Penn State. The authors would also like to acknowledge the assistance provided by B. Videto and C. Fetting in making the fluorescence measurements used to characterize the degree of incomplete mixing.

\section{$\underline{\text { References }}$}

1. Armstrong, E. S., "Ignition Systems for Liquid Oxygen (LOX)/Hydrocarbon Booster Engines," NASA TM 10233, 1989.

2. Miziolek, A. W., and Sausa, R. C., "Photochemical Ignition Studies: I. Laser Ignition of Flowing Premixed Gases," Ballistic Research Laboratory, BRL-TR-2644, 1985.

3. Lavid, M., and Stevens, J. G., "Photochemical Ignition of Premixed Hydrogen/Oxidizer Mixtures with Excimer Lasers," Comb. \& Flame, Vol. 60, No. 2, pp. 195-202, May 1985.

4. Poulos, A. T., and Lavid, M., "Infrared Laser-Induced Activation of Natural Gas," Fall Meeting of the Eastern States Section of the Combustion Institute," 1989.

5. Hill, R. A., "Ignition-Delay Times in Laser Initiated Combustion," Applied Optics, Vol. 20, No. 13, pp. 2239-2242, 1 July 1981 .

6. Trott, W.M., "CO ${ }_{2}$ Laser Induced Deflagration of Fuel/Oxygen Mixtures," Journal of Applied Physics, Vol. 54, No. 1, January 1983.

7. Raffel, B., Warnatz, J., and Wolfrum, J., "Experimental Study of Laser-Induced Thermal Ignition in $\mathrm{O}_{2} / \mathrm{O}_{3}$ Mixtures," Applied Phys. B., Vol. 37, pp. 189-195, 1985.

8. Maas, U., Raffel, B., Wolfrum, J., and Warnatz, J., "Observation and Simulation of Laser Induced Ignition Processes in $\mathrm{O}_{2}-\mathrm{O}_{3}$ and $\mathrm{H}_{2}-\mathrm{O}_{2}$ Mixtures," Twenty-first Symposium (International) on Combustion, The Combustion Institute, pp. 1869-1876, 1986.

9. Lee, J. H., and Knystautas, R., "Laser Spark Ignition of Chemically Reactive Gases," AIAA Journal, Vol. 7, No. 2, pp. 312-317, 1969.

10. Bach, G. G., Knystautas, R., and Lee, J. H., "Direct Initiation of Spherical Detonations in Gaseous Explosives," Twelfth Symposium (International) on Combustion, pp. 853-864, 1969. 
11. Weinberg, F. J., and Wilson, J. R., "A Preliminary Investigation of the Use of Focused Laser Beams for Minimum Ignition Energy Studies," Proc. Roy. Soc. London, Ser. A 321, 41-52, 1971.

12. Hickling, R., and Smith, W. R., "Combustion Bomb Tests of Laser Ignition," SAE Paper 740114, 1974.

13. Dale, J. D., Smy, P. R., and Clements, R. M., "Laser Ignited Internal Combustion Engine - An Experimental Study," SAE Paper 780329, 1978.

14. Seitzman, J. M., Paul, P. H., and Hanson, R. K., "Digital Imaging of Laser-Ignited Combustion," Paper 88-2775, AIAA Thermophysics, Plasmadynamics, and Lasers Conference, San Antonio, June 1988.

15. Spiglanin, T. A., Crofton, M. A., Fournier, E. W., Syage, J. A., and Cohen, R. B., "Laser Ignition of Hydrogen/Air Mixtures," WSSCI Meeting, March 1991.

16. Ho, C. M., and Santavicca, D. A., "Comparison of Laser Spark and Electrode Spark Ignition in Laminar Propane-Air Mixture," ESSCI Meeting, Fall 1990.

17. Ho, C. M., and Santavicca, D. A., "Laser-Induced Spark Ignition of Premixed Hydrocarbon Fuels," submitted to Comb. \& Flame, 1991.

18. Videto, B. D., and Santavicca, D. A., "A Turbulent Flow System for Studying Turbulent Combustion Processes," Comb. Sci. and Tech., Vol. 76, p. 159, 1991.

19. - Huntzinger, G. O. and Rigsby, G. E., "HEI--A New Ignition System Through New Technology," SAE Paper No. 750346, 1975.

20. Maly, R. and Vogel, M., "Initiation and Propagation of Flame Fronts in Lean $\mathrm{CH}_{4}$-Air Mixture by the Three Modes of the Ignition Spark, " Proceedings of the Seventeenth Symposium (International) on Combustion, pp. 821-831, The Combustion Institute, 1979.

21. Taylor, G. I., "The Formation of a Blast Wave by a Very Intense Explosion II. The Atomic Explosion of 1945," Proc. Roy. Soc. London, Ser. A 201, 175, 1950.

22. Khitrin, L. N., Moin, P. B., Smirnov, D. B., and Shevchuk, V. U., "Peculiarities of Laminar- and Turbulent-Flame Flashbacks," Tenth Symposium (International) on Combustion, pp. 1285-1291, The Combustion Institute, 1965.

23. Law, C. K., "Dynamics of Stretched Flames," Twenty-Second Symposium (International) on Combustion, pp. 1381-1402, The Combustion Institute, 1988.

24. Tsuruda, T. and Hirano, T., "Local Flame Front Disturbance Development Under Acceleration," Combustion and Flame, Vol. 84, pp. 66-72, 1991. 


\begin{tabular}{||l|l|l|l|l||}
\hline$\phi$ & $\mathrm{T}_{\mathrm{b}}(\mathrm{K})$ & $\rho_{\mathrm{u}} / \rho_{\mathrm{b}}$ & $\mathrm{S}_{\mathrm{L}}(\mathrm{m} / \mathrm{s})$ & $\mathrm{K}_{\text {Lam }}(\mathrm{m} / \mathrm{s})$ \\
\hline 0.6 & 2933.6 & 9.906 & 4.50 & 44.577 \\
\hline 1.0 & 3053.3 & 10.310 & 5.50 & 56.705 \\
\hline 1.4 & 3011.7 & 10.170 & 3.75 & 38.138 \\
\hline
\end{tabular}

Table 1. Test Conditions

\begin{tabular}{||c|c|c|}
\hline Breakdown Energy (mJ) & Measured Radius (mm) & Model Prediction (mm) \\
\hline 0.8 (HEI) & 1.2 & 0.91 \\
\hline 10.0 (laser spark) & 2.0 & 1.50 \\
\hline 40.0 (laser spark) & 2.5 & 1.98 \\
\hline
\end{tabular}

Table 2. Comparison between measured and Taylor spherical blast wave model for the kernel radius at $1 \mu s$

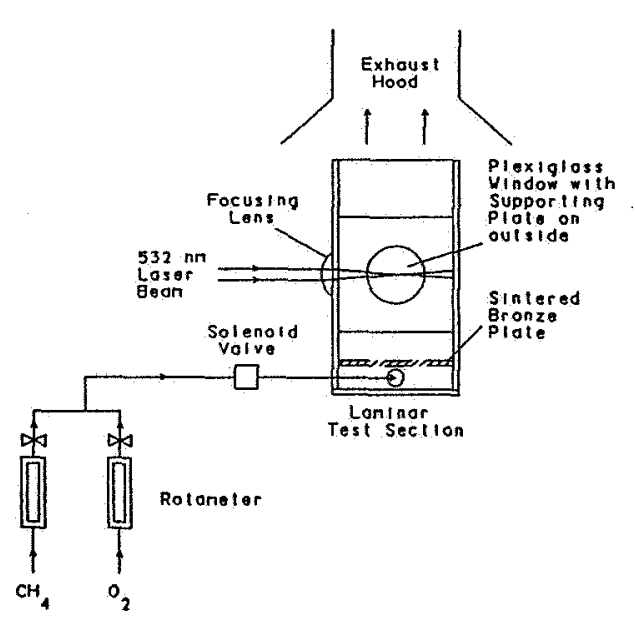

Figure 1. Experimental setup for laminar $\mathrm{CH}_{4} / \mathrm{O}_{2}$ flow

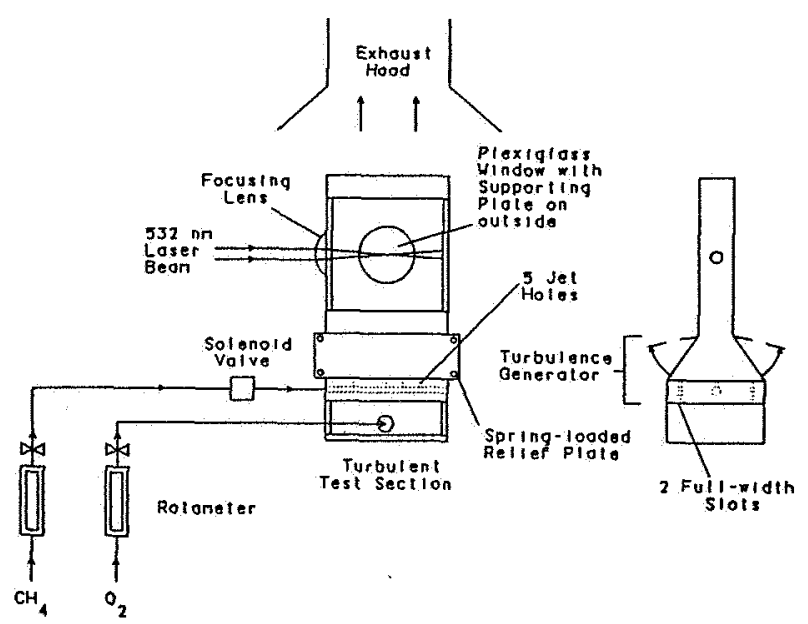

Figure 2. Experimental setup for turbulent $\mathrm{CH}_{4} / \mathrm{O}_{2}$ flow 




Figure 3. Spark Efficiency for $532 \mathrm{~nm}$ laser pulse at $10 \mathrm{~Hz}$ in air using various condensing lenses

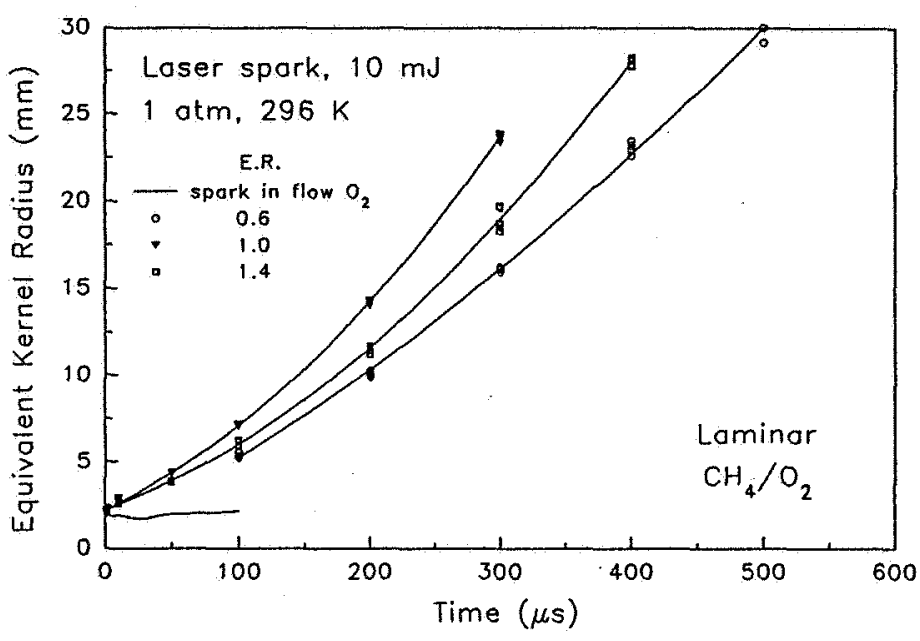

Figure 4. Equivalent kernel radius versus time: $10 \mathrm{Mj}$, laser spark, laminar

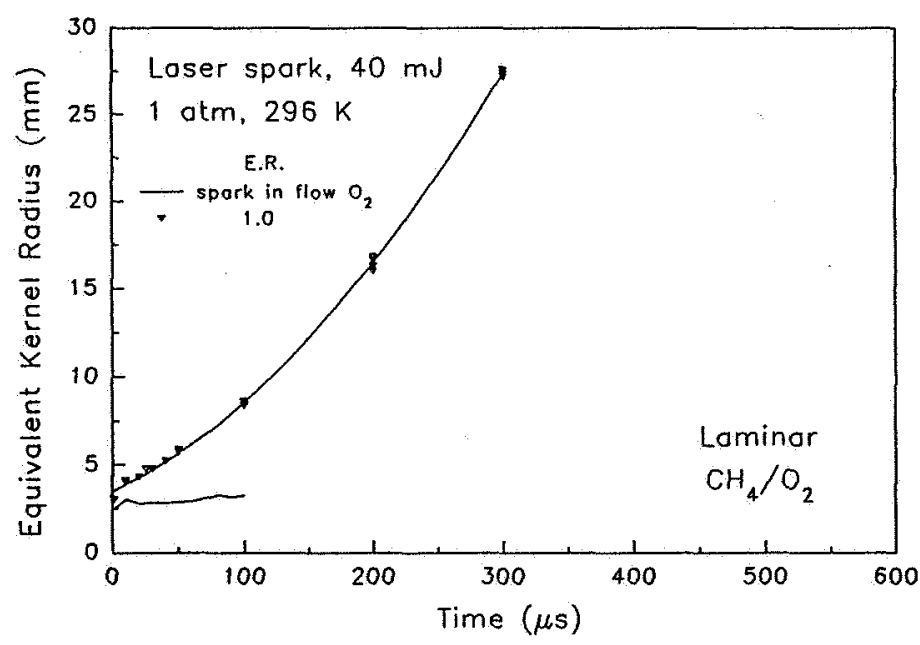

Figure 5. Equivalent kernel radius versus time: $40 \mathrm{~mJ}$, laser spark, laminar

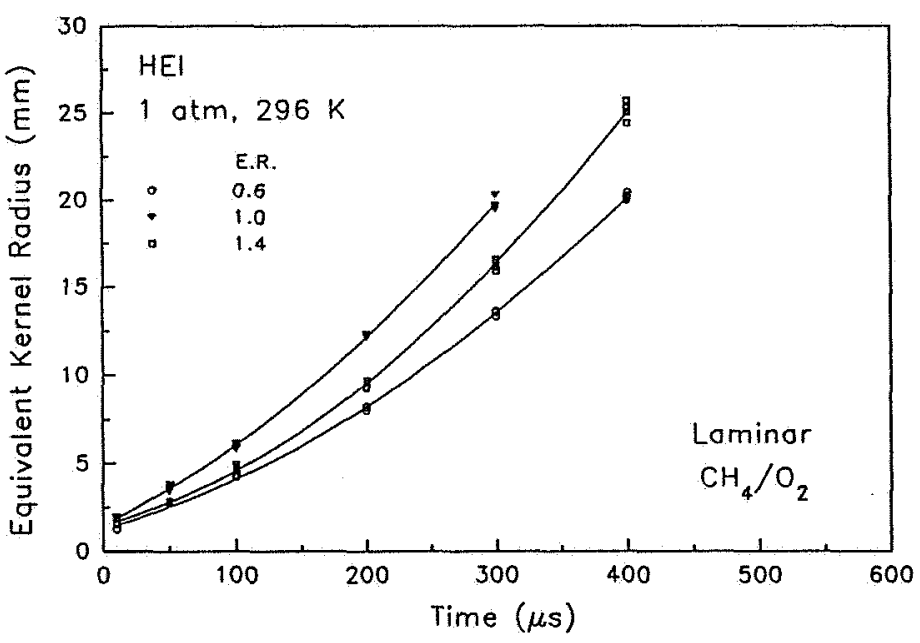

Figure 6. Equivalent kernel radius versus time: 7 $\mathrm{mJ}$ effective, HEI, laminar 


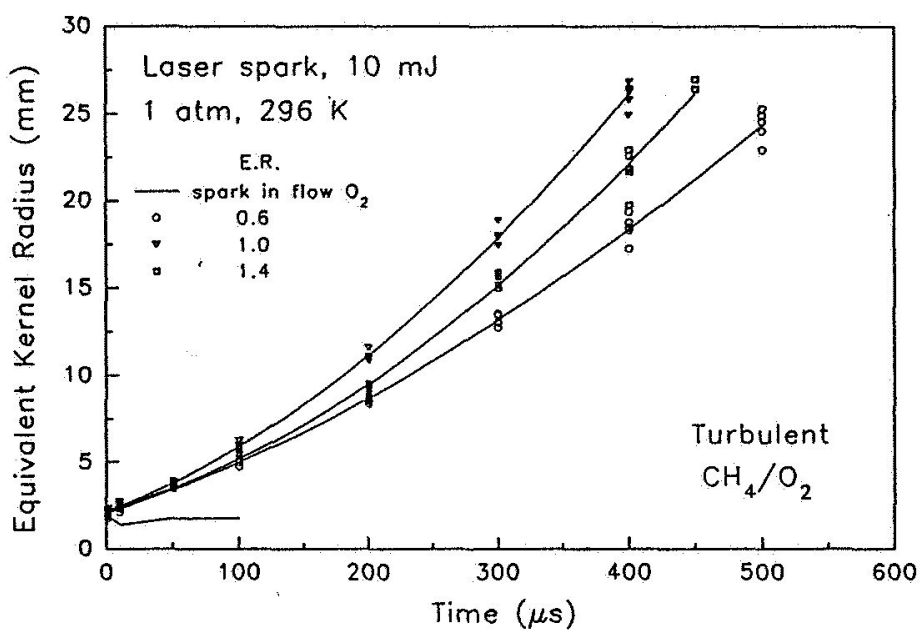

Figure 7. Equivalent kernel radius versus time: $10 \mathrm{~mJ}$, laser spark, turbulent

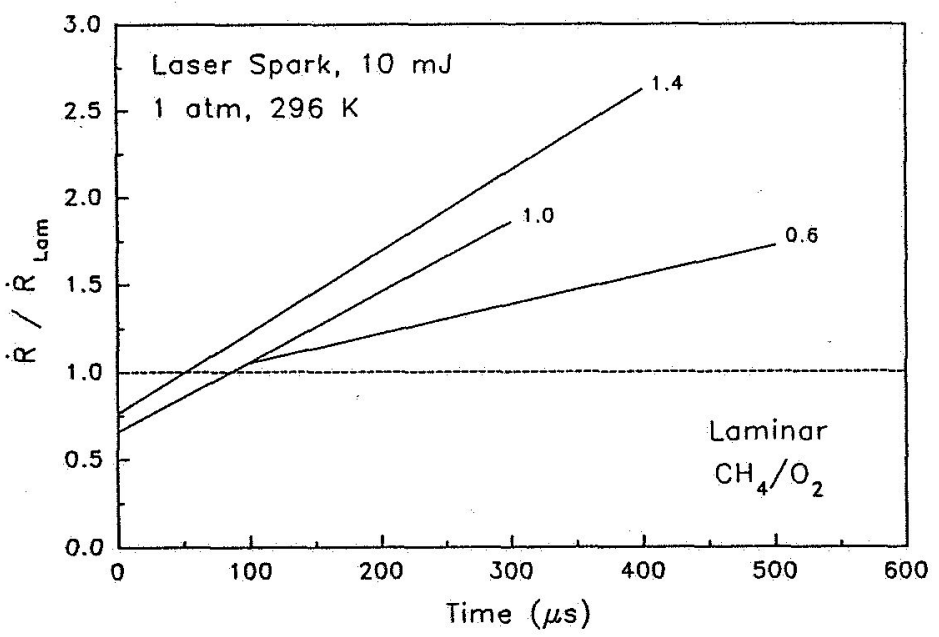

Figure 9. Normalized growth rate versus time: 10 $\mathrm{mJ}$, laser spark, laminar

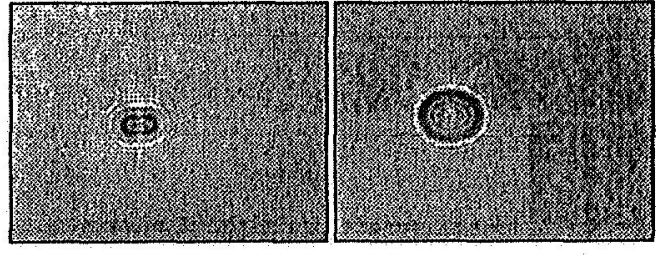

$50 \mathrm{~ns}$

$1 \mu \mathrm{s}$

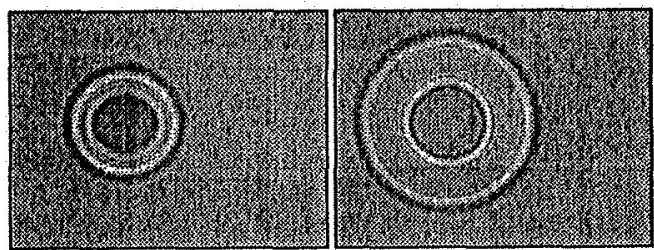

$5 \mu s$

$10 \mu \mathrm{s}$

Figure 8. Shadowgraph images: Laser spark, 10 $\mathrm{mJ}$, in laminar $\mathrm{Ch}_{4} / \mathrm{O}_{2}, 4 \mathrm{~cm} / \mathrm{s}$, e.r. $=$ 1.0 , field of view $20.25 \times 15.5 \mathrm{~mm}$

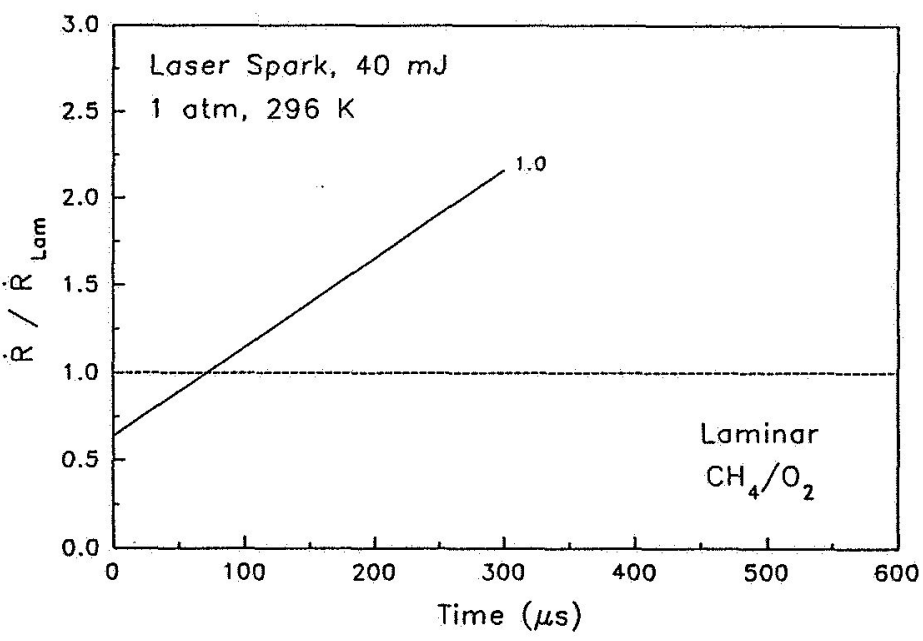

Figure 10. Normalized growth rate versus time: 40 $\mathrm{mJ}$, laser spark, laminar 


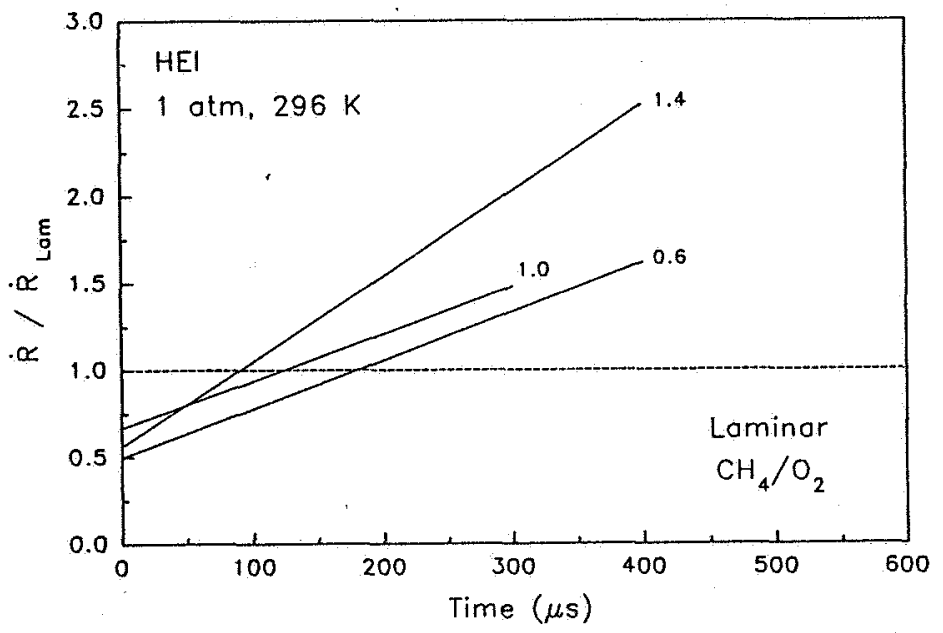

Figure 11. Normalized growth rate versus time: 7 $\mathrm{mJ}$ effective, HEI, laminar

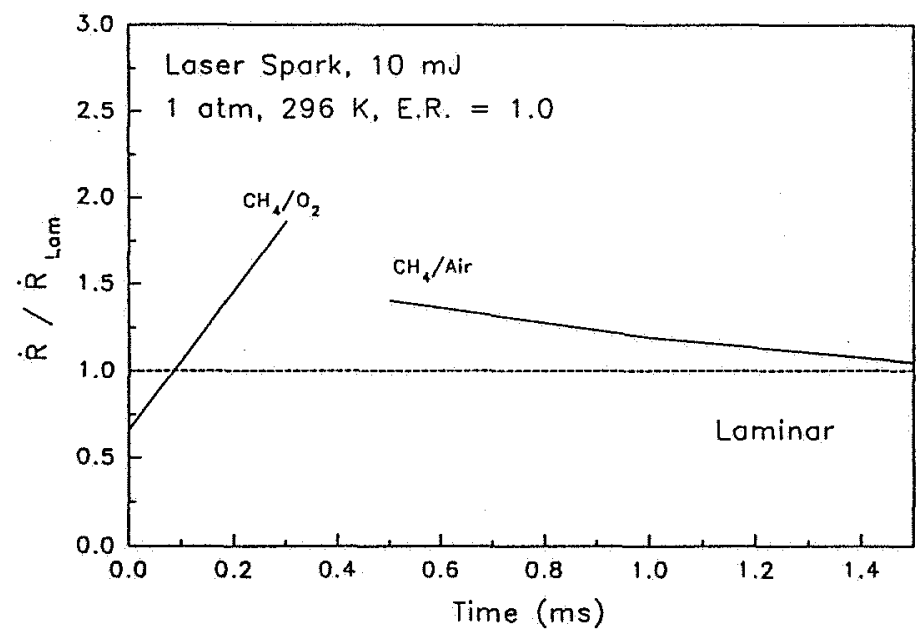

Figure 13. Normalized growth rate comparison for $\mathrm{CH}_{4} / \mathrm{O}_{2}$ and $\mathrm{CH}_{4} /$ Air: $10 \mathrm{~mJ}$ laser spark, e.r. $=1.0$

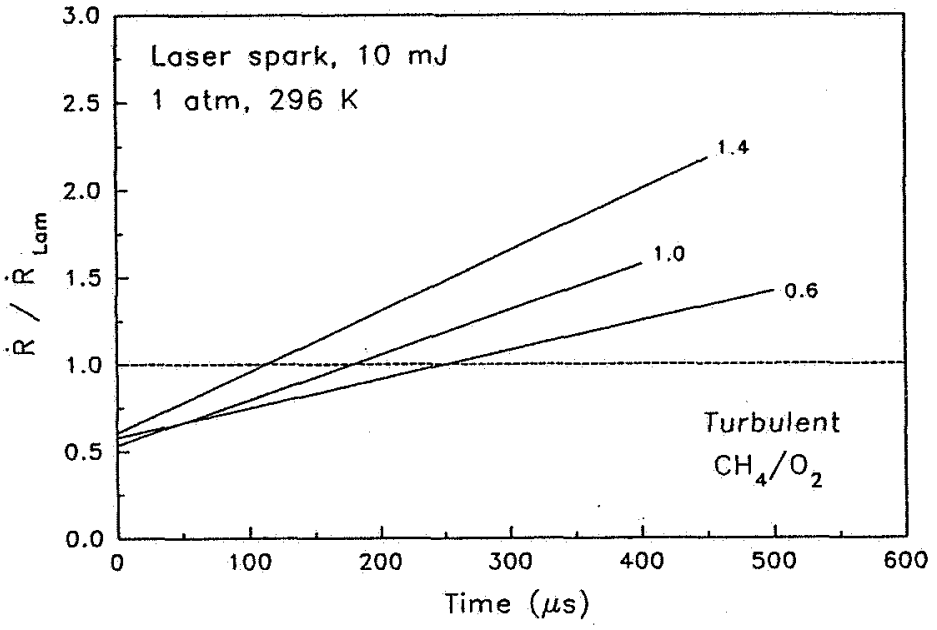

Figure 12. Normalized growth rate versus time: 10 $\mathrm{mJ}$, laser spark, turbulent

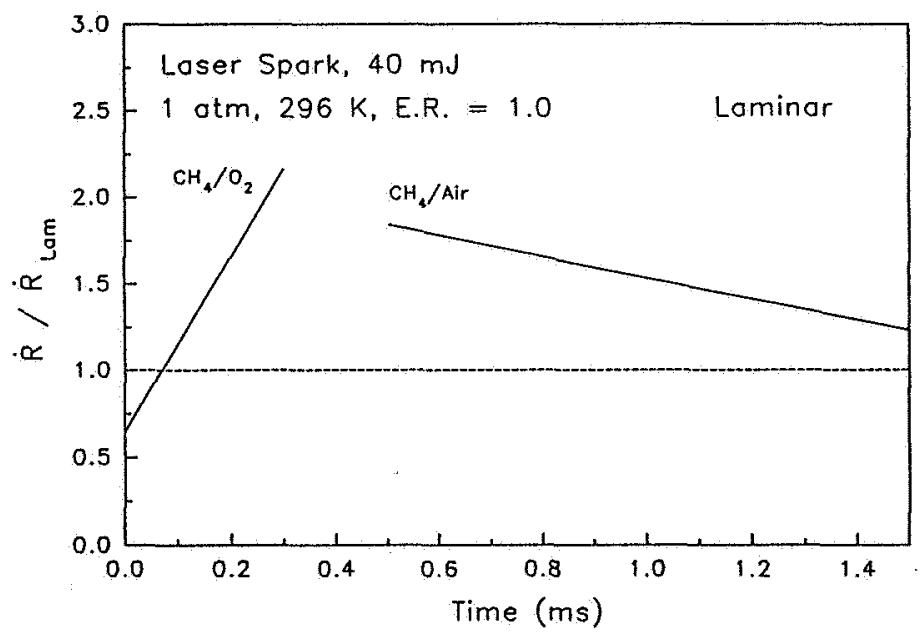

Figure 14. Normalized growth rate comparison for $\mathrm{CH}_{4} / \mathrm{O}_{2}$ and $\mathrm{CH}_{4} / \mathrm{Air}: 40 \mathrm{~mJ}$ laser spark, e.r. $=1.0$ 


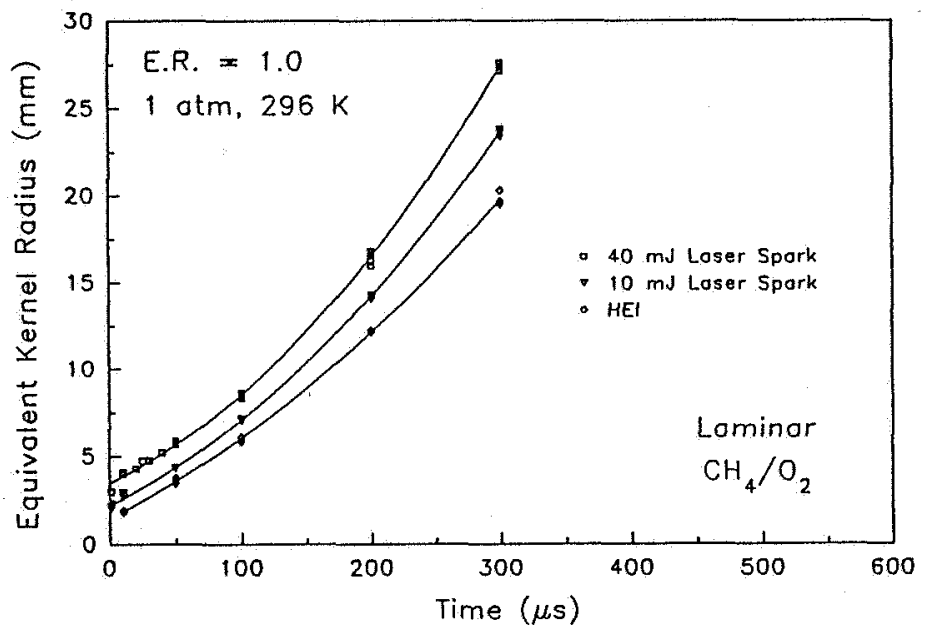

Figure 15. Comparison between ignition systems: HEI, 10 and $40 \mathrm{~mJ}$ laser spark (laminar, e.r. $=1.0)$

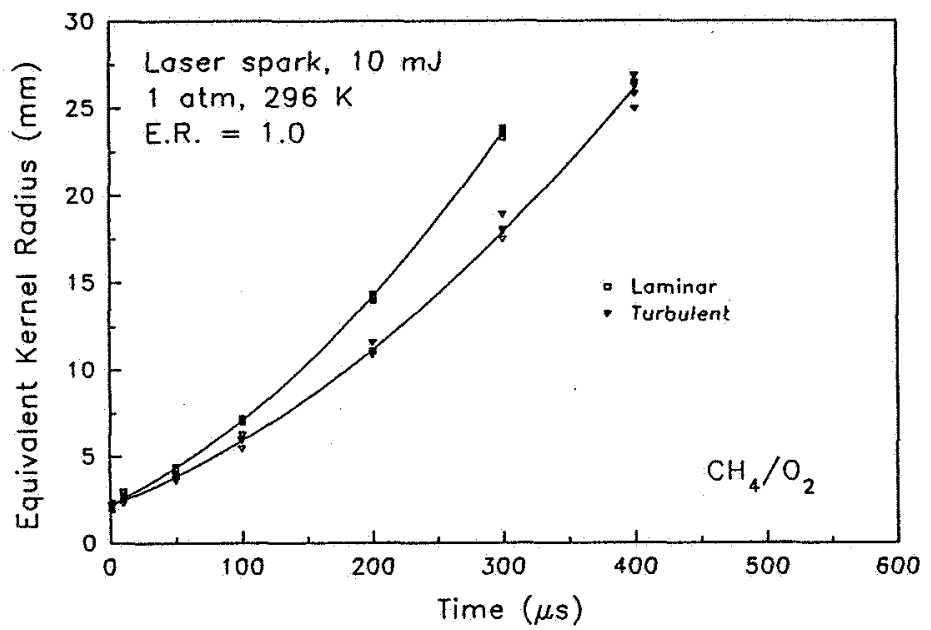

Figure 16. Comparison between laminar and turbulent flow: $10 \mathrm{~mJ}$ laser spark, e.r. $=1.0$ 